\title{
Design and Analysis of the Ballast of Metal Halide Lamp
}

\author{
Z.J.Jia \\ State Grid Sichuan Electric Power Research Institute, Chengdu, P. R. China
}

\begin{abstract}
The metal halide lamp is one of the best energy-saving and environment-protective illumination plans to substitute traditional light sources with high energy consumption. Electronic ballast is essentially the power supply for metal halide lamp, so it has great significance to develop high-performance electronic ballast fit for metal halide lamp. In this paper, on the basis of brief analysis on discharge characteristics of metal halide lamp, the operation principle and control strategy of the electronic ballast for $70 \mathrm{~W}$ metal halide lamp are given out in detail. Waveforms gained from measurements of key points in the circuit show the metal halide lamp can be ignited gradually and work stably.
\end{abstract}

KEYWORD: electronic ballast; metal halide lamp; power factor correction; topological structure

\section{INTRODUCTION}

With the ever-increasing awareness of energy saving and environmental protection, metal halide lamp is extensively applied in illumination system. Electronic ballast is essentially the power supply for metal halide lamp. The performance index and power factor of electronic ballasts in practical use can't reach anticipated values, which can be explained by reasons as follows. (a) The ignition process of metal halide lamp is complicated; (b) after the lamp is ignited, electronic ballast always works during the long start-up process that load resistance varies much; (c) electronic ballast has lots of operation modes and can't be optimized to the best.

This paper addresses a novel method to design and analyze the ballast of metal halide lamp. The operation principle, function realization, hardware choice, program design and work process of electronic ballast are introduced by turns.

\section{OPERATION PRINCIPLE OF THE BALLAST}

Developing electronic ballast should be on the basis of the study on discharge characteristics of metal halide lamp. The ignition mode and control strategy of ballast are both determined by discharge characteristics of the lamp.

Firstly, metal halide lamp in usual discharge condition presents negative volt-ampere characteristic. If the lamp is connected to the grid independently, then it works unstably. The combination of the lamp and ballast can overcome this disadvantage. Secondly, metal halide lamp should be repeatedly ignited because it's quenched every half period at power frequency. Thirdly, the instant relationship between the voltage and current of lighting tube during one working period can be linear if the lamp is at high frequency.

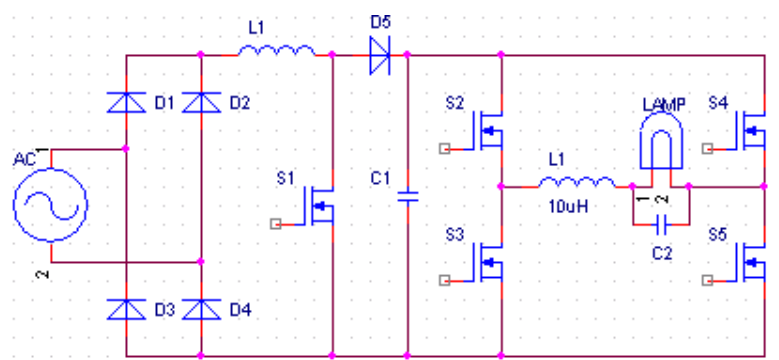

Figure 1. The simplified structure of electronic ballast with two-stage topology

Considering the discharge characteristics of metal halide lamp, the basic topology structure of the ballast is determined as follows. Two-stage topology is introduced in design of electronic ballast, as is shown in Fig. 1. The first stage is power factor correction and dc boost chopper. The second stage is buck and half-bridge inverter. This topology structure is relatively simple and high efficient.

The ignition principle of the circuit is to use high voltage produced by LC series resonance to start the metal halide lamp, and then utilize the differences of impedance characteristics before and after the startup of the lamp to make the resonant circuit mismatched naturally. Finally, the lamp can reach the stable working state. 
The start-up control includes constant voltage control before start-up and constant current control during start-up. The constant voltage control mainly guarantees that no-load output voltage of buck circuit keeps at a fixed value before the lamp is really ignited. The value of no-load output voltage is determined by output capacitance of buck circuit. The constant current control can be achieved by the control of peak value of buck's input current.

The steady-state control is mainly constant power control. The average current detection circuit is added to input terminal of buck circuit. According to the current detected, duty ratio of high-frequency switch of inverter is adjusted. Thus constant power control is achieved by indirect control.

\section{FUNCTION REALIZATION AND HARDWARE CHOICE OF THE BALLAST}

The main circuit is composed of three parts, i.e. EMI filtering and full-bridge rectifier circuit, power factor correction and dc boost chopper, buck and halfbridge inverter. Except for the main circuit, electronic ballast includes control circuit. The control circuit is composed of sample-and-contrast circuit, digital control circuit. In addition, LC resonant ignition circuit is the important part of the ballast.

EMI filtering circuit plays a notable role in suppressing common mode and differential mode interference. According to parameter comparison in tests, the value of common mode filter capacitor is fixed at $47 \mathrm{nF}$ and the value of differential mode filter capacitor is set at $3300 \mathrm{pF}$. Mn- $\mathrm{Zn}$ ferrite is chosen as the magnetic core material of common mode inductance. Fe-Si-Al magnetic powder core is chosen as the magnetic core material of differential mode inductance. The filter capacitor parallel with the output terminal of full-bridge rectifier is $224 \mathrm{nF}$ in capacitance. Thus the pulse dc can be obtained.

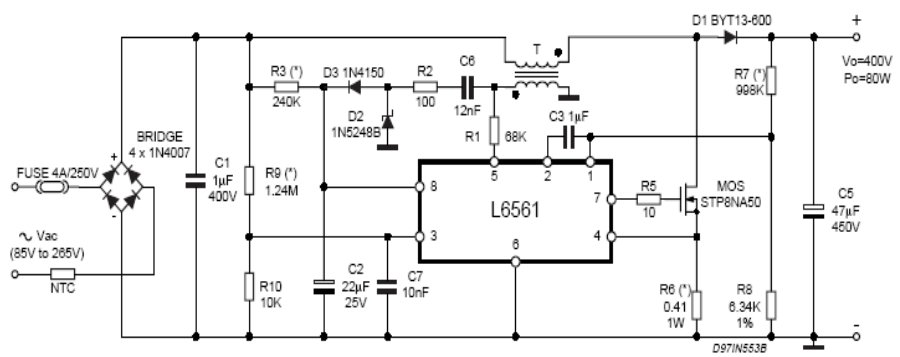

Figure 2. APFC and dc boost chopper of electronic ballast

L6561 PFC chip is the core of the active power factor correction (APFC) circuit. It can not only suppress the waveform distortion of input source current, but assure that wave crest coefficient of tube current is smaller than 1.7. The power factor of electronic ballast under rated power can be up to 0.97 after active power factor correction. The circuit diagram is shown in Fig. 2.
APFC and dc boost chopper is composed of boost inductance $\mathrm{T}$, power MOSFET, boost diode D1, front filter capacitor $\mathrm{C} 2$, end filter capacitor $\mathrm{C} 5$, L6561 PFC chip and peripheral circuits. The innerand-outer loop control mode is adopted. The inner loop is composed of R9 and R10. It's used to not only track sinusoidal variation of input voltage but adjust working frequency of boost inductance to keep the input average current sinusoidal. The outer loop is composed of R7 and R8. It's used to adjust not only output duty ratio of APFC controller but rated value of output voltage $\mathrm{V} 0$.

The output voltage of dc boost chopper ought to at least $15 \%$ higher than the peak value of input voltage, so that working frequency isn't reduced to the range of audio frequency. The dc output voltage is about $400 \mathrm{~V}$ corresponding to ac input voltage of $230 \mathrm{~V}$. Fast recovery diode should be chosen as the boost diode D1 which is the important part of dc boost chopper. Reverse recovery time of D1 should be smaller than 300ns. Delay time of turn-off should be smaller than $150 \mathrm{~ns}$ for power MOSFET.

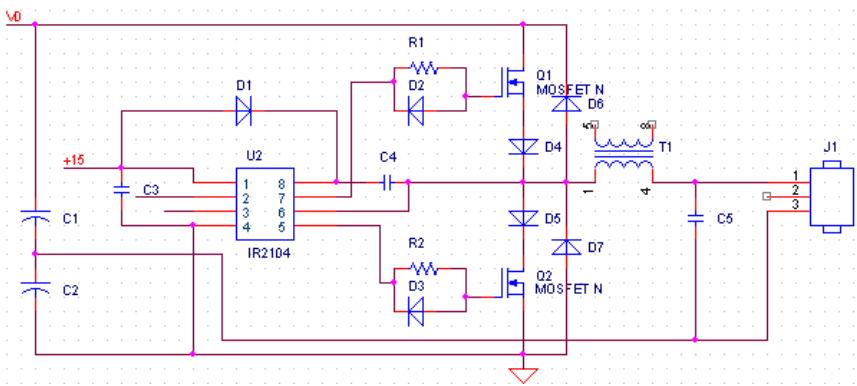

Figure 3. Buck and half-bridge inverter of electronic ballast

The buck and half-bridge inverter is as shown in Fig. 3. IR2104 is the driver IC for half-bridge inverter. The resonant inductance and capacitor of resonant ignition circuit are $\mathrm{T} 1$ and $\mathrm{C} 5$ respectively. $\mathrm{C} 1$ and $\mathrm{C} 2$ substitute two MOSFET with quite slow switching speed in full-bridge inverter. Dc voltage of $400 \mathrm{~V}$ is transformed into a series of high-frequency square waves by half-bridge inverter. The voltage to earth of the point between $\mathrm{C} 1$ and $\mathrm{C} 2$ is $\mathrm{V} 0 / 2$. If MOSFET Q1 and Q2 are under the control of periodical square waves, then dc voltage of $400 \mathrm{~V}$ is turned into high-frequency square waves with peakto-peak value of $\mathrm{V} 0$.

Diodes D6 and D7 are not only the channel of energy feedback from load to dc side but make load current continuous, so fast recovery diode with withstand current of $2 \mathrm{~A}$ is selected as the diode. Because metal halide lamp is the resistanceinductance load of half-bridge voltage-source inverter at ac side and requires reactive power provided, electrolytic capacitors with large capacity of $\mathrm{C} 1$ and $\mathrm{C} 2$ at dc side are used to cushion the reactive power. MOSFET is used as switching device because of its thermal stability, fast switching speed and large safe operating area.

The working process of the circuit is analyzed as 
follows. Two MOSFET of Q1 and Q2 are in the alternate condition of high-speed turn-on and turnoff. Reverse recovery problem occurs at the time of turn-off of diodes, which can greatly increase switching loss of the device. The buck and halfbridge inverter is working at discontinuous current mode to avoid occurrence of above situation. If Q1 is working at high frequency mode and Q2 is at turnoff mode, the circuit has three working state.

If Q1 is at turn-on mode and Q2 is turned off, the circuit is equivalent to buck circuit. Drain voltage of Q1 is dc $400 \mathrm{~V}$, as is shown in Fig. 4. At this time, the current goes through Q1, D4, primary winding of $\mathrm{T} 1$, lamp $\mathrm{J} 2$ and $\mathrm{C} 1$ by turns. $\mathrm{C} 1$ provides energy for energy storage of $\mathrm{T} 1$ and light-and-heat emission of the lamp. Lamp current is gradually increased.

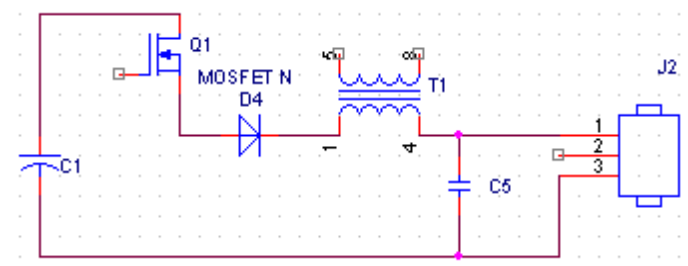

Figure 4. Working state I

If Q1 and Q2 are both turned off, working state of the circuit is changed. Because the current going through primary winding of $\mathrm{T} 1$ can't be changed abruptly, the current goes through primary winding of T1, lamp J1, C2 and D7 by turns, as is shown in Fig. 5. At this time, magnetic field energy stored in primary winding of $\mathrm{T} 1$ is transformed into electric field energy of $\mathrm{C} 2$ and energy consumed by lamp impedance. Lamp current is gradually decreased.

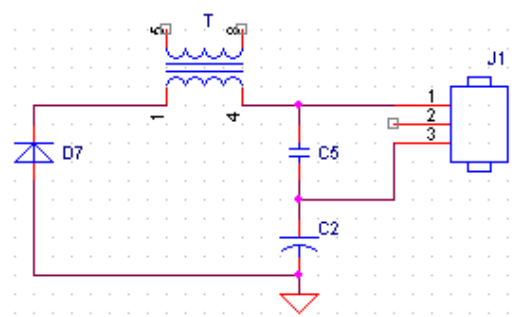

Figure 5. Working state II

If the turn-off of Q1 and Q2 lasts a long time, the current going through primary winding of $\mathrm{T} 1$ is decreased to zero. At this time, energy stored in resonant capacitor C5 is supplied to the lamp.

If Q2 is at high-frequency switch mode and Q1 is turned off, working process of the circuit is similar to analysis above.

According to the analysis above, half-bridge inverter can be equivalent to buck circuit every half low-frequency period, so half-bridge inverter can not only provide the lamp with appropriate operating voltage but make the lamp work at low-frequency square-wave mode. The output of buck and halfbridge inverter is directly connected to series resonant ignition circuit. T1 is winded into the shape of transformer, but actually it's the resonant inductance.

The ignition process needs real-time closed-loop control. Because metal halide lamp requires constant current control during start-up process and constant power control during steady stage, it's necessary to real-time sample the current going through the lamp and compare it with reference. Data sampling and comparison process is accomplished by sampling and comparison circuit of which the core is the chip LM392. LM392 is an integrated chip. It's composed of high-gain operational amplifier and voltage comparator. The result obtained by comparison is input to PIC microcontroller for analysis. The response of microcontroller is output to corresponding port to control the work of inverter's driver IC, i.e. control the chip IR2104's high-level enabling port and input wave of the IN pin. The whole input wave of the IN pin is from PIC microcontroller, as is shown in Fig. 6.

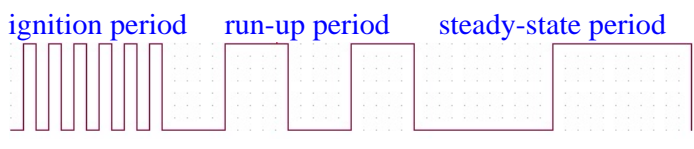

Figure 6. The input wave of the IN pin controlled by PIC microcontroller

The whole operation process of the control system is as follows. The first stage is pre-ignition period. After electronic ballast is energized, PIC microcontroller start to run system examination and establishment. The second stage is ignition period. The ballast sends ignition pulse to resonant circuit under the control of microcontroller. High voltage as high as several kilovolts is generated instantly at both ends of metal halide lamp. The dielectrics of the lamp is broken down and the lamp is ignited. If the detection of lamp current doesn't reach the specified value, the ignition is done again. The third stage is run-up period. If the lamp is really ignited, the lamp is at the state of low resistivity and the lamp voltage is reduced sharply. On one hand, if lamp current is too low, then the lamp is quenched. On the other hand, if lamp current is too high, then the lamp electrodes is melted. Therefore, repetitive bulb collapse detection is carried out to keep lamp current constant. The fourth stage is steady-state period. The output of electronic ballast reaches nominal voltage and current and the lamp work normally. Repetitive bulb collapse detection and closed-loop control are carried out to keep the lamp at constant power state.

\section{WORKING PROCESS OF THE BALLAST}

The working process of $70 \mathrm{~W}$ metal halide lamp is closely linked to software flow written in PIC microcontroller. Its working process can be explained by waveform graph measured in tests. Fig. 7,8 and 9 show respectively the performances of 
voltage waveforms of metal halide lamp during the periods of ignition, run-up and steady-state.

Fig. 7 shows general view of voltage waveform of the lamp during the period of ignition. On the starting moment, the inner metal halide lamp is an open circuit, so the resonant voltage amplitude is as high as one kilovolt and resonant frequency is quite high. Although the first round of resonant ignition fails, the breakdown of the lamp occurs. At the moment, the lamp resistance reduces sharply so that lamp voltage is quite small and obviously lower than first-round ignition voltage. Because the lamp current is too small to maintain arc-discharge stable, the ignition is done again according to software flow. Except for the first-round ignition, resonance doesn't occur in resonant circuit in the following ignition process. Only the sweep frequency program of PIC microcontroller runs repeatedly to increase the lamp current. On the right side of the graph, the ignition succeeds and the period of run-up begins.

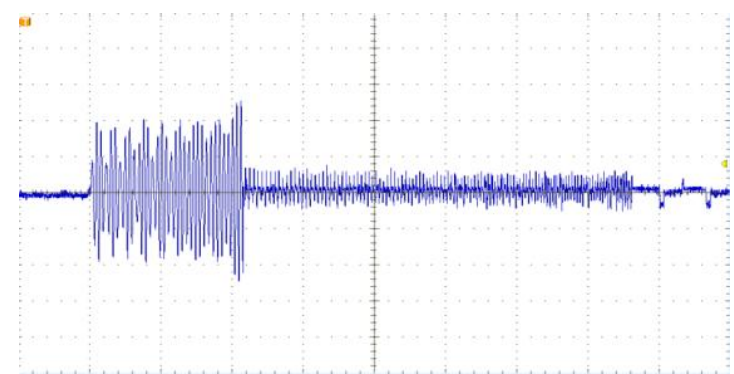

Figure 7. General view of voltage waveform of the lamp during the period of ignition

Fig. 8 shows local circumstance of voltage waveform of the lamp during the period of run-up. Periodical bulb collapse detection runs repeatedly to inspect whether the value of lamp current is zero or too small. If the arc is extinct, then sweep-frequency series resonant ignition runs again. The inspection is required to repeat several times until the arc of the lamp becomes stable. From Fig. 2, bulb collapse detection runs at the end of each relatively long periodical square wave. The waveform yellow arrow points to indicates that the 5th inspection of PIC microcontroller fails and sweep-frequency resonant ignition program automatically runs.

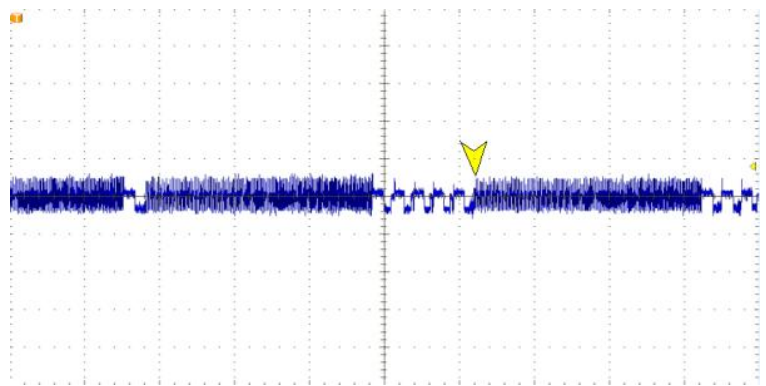

Figure 8. Local circumstance of voltage waveform of the lamp during the period of run-up

Fig. 9 shows general view of voltage waveform of the lamp during one period of steady-state. The voltage waveform of the lamp is a series of square wave of which the period is basically invariable. However, the frequency of square wave during the period of steady-state is much smaller than that during the period of run-up. Bulb collapse detection runs at the end of each periodical square wave. If the arc is extinct, then the detection repeats. Automatic shutdown program runs if the arc is still extinct after fixed detection times. The strategy of low-frequency square-wave ignition is adopted to avoid the occurrence of acoustic resonance during the period of steady-state.

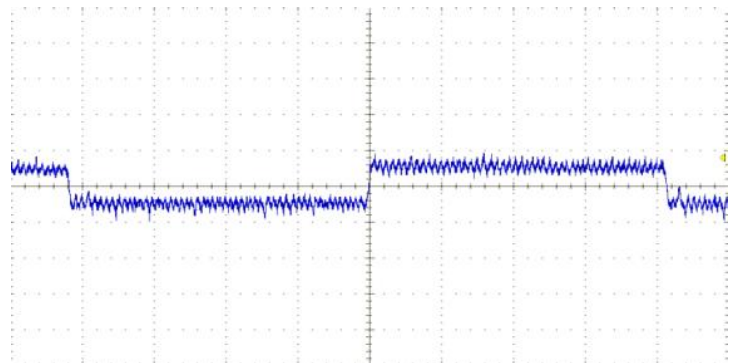

Figure 9. General view of voltage waveform of the lamp during one period of steady-state

\section{CONCLUSION}

Two types of chips are adopted in the design of control part of electronic ballast of metal halide lamp. On one hand, L6561 PFC chip is used for active power factor correction and to provide the lamp with necessary voltage and current. On the other hand, PIC microcontroller is the core of electronic ballast in real-time closed-loop control. It plays a main role in constant current control during start-up process and constant power control during steady stage.

The practical operation demonstrates that the ballast can work stably and power factor can be promoted to 0.97 under rated power. The output power of the ballast can be kept at 70w during steady stage. The electronic ballast conforms to correlative national standards such as "Electromagnetic compatibility- Limits- Limits for harmonic current emissions", etc.

\section{REFERENCES}

[1] Dong Jiqing, Chen Wei, 2005. A novel EMI integrated filter. Journal of Jimei University (Natural Science) 10(2): $1-4$.

[2] Shi Shoudong, Zhang Liang, Sheng Meng, 2006. Design and analysis of HID ballast. China Illuminating Engineering Journal 17(3): 24-27.

[3] Xu Genda, 2006. Research on novel frequency modulation drive electronic ballast for HID lamps based on IR2104. Power Supply Technologies and Applications 9(9): 23-27.

[4] Zhang Weiping, Guan Xiaohan, Zhao Xusen, et al, 2006. The controlling strategy for electronic ballast of HID Lamps. IEEE IPEMC 1: 1-5.

[5] Zhang Weiping, Zhao Xusen, Wu Zhaolin, 2000. A flexible DC link-global soft switch-full bridge inverter for MH lamps. Power Electronics and Motion Control Conference 1: 424-429. Beijing, China. 